\title{
INHIBITIVE EFFECT OF Mussaenda frondosa LEAVES EXTRACT ON MILD STEEL CORROSION-STATISTICAL AND THEORETICAL VIEW
}

\author{
S. Jyothi ${ }^{{ }^{*}}$, K. Rathidevi ${ }^{1}$, D. Jalajaa ${ }^{1}$ and P. S. Samuel Ratnakumar ${ }^{2}$ \\ ${ }^{1}$ Department of Science and Humanities, Chemistry division, Kumaraguru College of \\ Technology, Coimbatore - 641049, Tamil Nadu, India. \\ ${ }^{2}$ Department of Mechanical Engineering, Kumaraguru College of Technology, \\ Coimbatore - 641049, Tamil Nadu, India. \\ *E-mail: jyothi.sci@kct.ac.in
}

\begin{abstract}
The statistical and theoretical view on mild steel (MS) corrosion in a sulphuric acid medium in the presence of leaves extract of Mussaenda frondosa (MF) were studied by electrochemical impedance spectroscopy and potentiodynamic polarization techniques. The nature of the inhibitor was defined by the polarization studies. The semicircle curves observed in electrochemical impedance spectroscopy indicated that the corrosion of mild steel is controlled by the charge transfer process. The corrosion inhibition performances enhanced by the addition of MF extract and increase with increase in the concentration of the MF extract. GCMS is used to gather the important phytochemical constituents in the MF extract. The adsorption of MF on the metal surface is confirmed by SEM images. DFT was performed in order to confirm the adsorption of the constituents in MF extract on MS.
\end{abstract}

Keywords: Mild steel; Adsorption; Corrosion; Potentiodynamic polarization; GC-MS; SEM.

(C) RASĀYAN. All rights reserved

\section{INTRODUCTION}

Mild steel (MS) is the extensively used materials in engineering mainly for the automobile and structural applications. Moreover, MS easily undergo rusting in the acidic and humid atmosphere and the rate of corrosion tend to become high ${ }^{1,2}$. Application of inhibitors on controlling metal corrosion that is in contact with an aggressive environment is an accepted practice. Many organic compounds have been used as corrosion inhibitor ${ }^{3}$. The compounds especially with hetero atoms such as nitrogen, sulphur and oxygen showed a better inhibition performance. But these compounds are toxic to living components and expensive too ${ }^{4,5}$. In order to overcome these problems 'Green Inhibitors' are in use. Plant extracts have become important because they are readily available, environmentally acceptable. They phyto ingredients in the plant extracts 3 have very greater inhibition efficiency and they are also cheap and safe inhibitors of corrosion of metals ${ }^{6}$. Hence in the present work, an effort has been made to use leaves extract of Mussaenda frondosa as a corrosion inhibitor for mild steel in $\mathrm{H}_{2} \mathrm{SO}_{4}$ medium using electrochemical impedance spectroscopy (EIS) and potentiodynamic polarization (PDP).

\section{Materials and Methods}

\section{EXPERIMENTAL}

The ethanol extract of MF dried leaves extract was collected, filtered from the soxhlet apparatus after 6 hours. The extract was concentrated by evaporation on a water bath $\left(\right.$ at $\left.60^{\circ} \mathrm{C}\right)$ until most of the ethanol is evaporated. Desired concentrations of inhibitor were prepared by dilution of crude extract of MF with ethanol. The electrochemical measurements were carried out using $\mathrm{CH}$ - Instrument Model-608D in a typical three-electrode system consisting of the MS specimen as working electrode, a platinum electrode as a counter electrode and saturated calomel electrode as a reference electrode. Electrochemical

Rasayan J. Chem., 12(1), 272-277(2019)

http://dx.doi.org/10.31788/RJC.2019.1214097

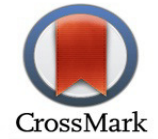


measurements were performed in a glass cell with mild steel, taken as the working electrode with an exposed area of $1 \mathrm{~cm}^{2}$. Before each experiment electrode was polished and degreased as per ASTM procedure 7 . GC-MS technique was carried out on a SHIMADZU QP-2010 Plus Gas ChromatographMass Spectrometer comprising an AOC-20i autosampler and gas chromatograph interfaced to a mass spectrometer. The adsorbed layer coated over the MS surface was authenticated by SEM. The statistical significance is measured by analysis of variance (ANOVA).

\section{RESULTS AND DISCUSSION}

The EIS is an effective tool to characterize the film coverage on the electrode, which measures double layer capacitance $\left(\mathrm{C}_{\mathrm{dl}}\right)$ and charge transfer resistance $\left(\mathrm{R}_{\mathrm{ct}}\right)$. The impedance responses are pictorially given in the form of Nyquist plots. The corrosion resistance of MS in $0.5 \mathrm{M} \mathrm{H}_{2} \mathrm{SO}_{4}$ in the absence and presence of MF extract was estimated and the respective Nyquist plots are presented in the Fig.-1. The data obtained from these figures are tabulated in the Table-1. The added MF extract in the test solution tends to change in impedance response behavior of MS. The impedance behavior of MS enhanced by the adsorption of MF molecules on the metal surface owing to increasing the surface coverage. ${ }^{8,9}$ These results inferred that increase in IE. Adsorbed the constituents present in MF extract molecules form protective films which inhibit corrosion and protect the metal surface. From the table, it is evident that on increasing concentrations of MF extract enhance the $R_{c t}$ values considerably and also reduce the $C_{d l}$ values. The increase in the resistance values tends to enhance the IE is due to the gradual displacement of $\mathrm{H}_{2} \mathrm{O}$ by the inhibitor molecules. In the presence of MF extract to that of the blank solution may tend to decrease the dielectric constant or increase the width of the double layer resulting decreases $\mathrm{C}_{\mathrm{dl}}$ values. Hence adsorptions of MF molecules on the metal surface leads to form the protective layer over the MS surface. ${ }^{10}$

Table-1: Polarisation and Impedance Data on MS Corrosion by Changing Concentrations of MF Extract in $0.5 \mathrm{M}$

\begin{tabular}{c|c|c|c|c|c|c|c|c}
\hline $\begin{array}{c}\text { MF Conc. } \\
(\mathrm{g} / \mathrm{L})\end{array}$ & $\begin{array}{c}\mathrm{I}_{\text {corr } x 10^{-3}} \\
\left(\mathrm{Amp} / \mathrm{cm}^{2}\right)\end{array}$ & $\begin{array}{c}\mathrm{b}_{\mathrm{a}} \\
(\mathrm{mV})\end{array}$ & $\begin{array}{c}\mathrm{b}_{\mathrm{c}} \\
(\mathrm{mV})\end{array}$ & $\begin{array}{c}-\mathrm{E}_{\mathrm{corr}} \\
\left(\mathrm{mV} \mathrm{dec}^{-1}\right)\end{array}$ & $\begin{array}{c}\mathrm{IE} \\
(\%)\end{array}$ & $\begin{array}{c}\mathrm{R}_{\mathrm{ct}} \\
\left(\Omega \mathrm{cm}^{2}\right)\end{array}$ & $\begin{array}{c}\mathrm{C}_{\mathrm{dl}} \\
\left(\mathrm{F} \mathrm{cm}^{-2}\right)\end{array}$ & $\mathrm{IE}(\%)$ \\
\hline 0 & 2.9920 & 165.837 & 199.92 & 521.3 & - & 14.24 & 0.00004869 & - \\
\hline 0.05 & 1.8130 & 147.929 & 201.05 & 512.1 & 39.4 & 33.38 & 0.00004760 & 57.3 \\
\hline 0.10 & 1.0190 & 131.096 & 183.65 & 506.5 & 66.0 & 64.19 & 0.00004230 & 77.8 \\
\hline 0.15 & 0.7250 & 124.084 & 173.73 & 504.4 & 75.7 & 79.52 & 0.00004105 & 82.0 \\
\hline 0.20 & 0.5663 & 117.495 & 167.31 & 502.3 & 81.0 & 92.79 & 0.00003757 & 84.6 \\
\hline 0.25 & 0.3898 & 110.338 & 151.49 & 502.3 & 87.0 & 111.1 & 0.00003325 & 87.1 \\
\hline
\end{tabular}

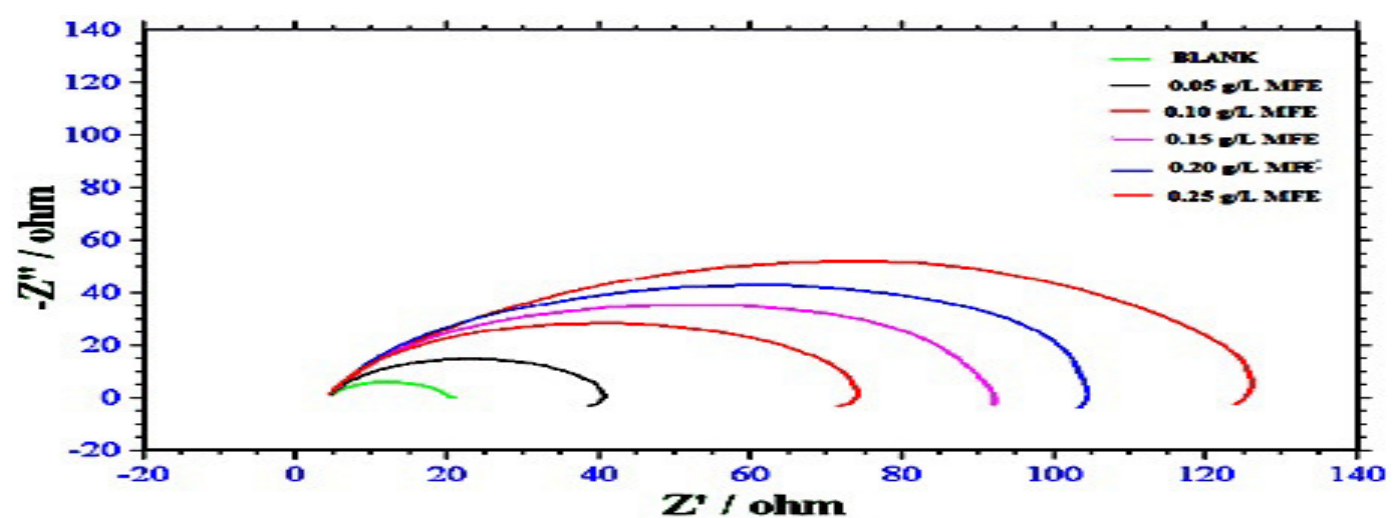

Fig.-1: Nyquist plots on MS Corrosion by Changing Concentrations of MF Extract in $0.5 \mathrm{M} \mathrm{H}_{2} \mathrm{SO}_{4}$

Figure- 2 shows the positive and negative polarization curves of mild steel in $0.5 \mathrm{M} \mathrm{H}_{2} \mathrm{SO}_{4}$ in addition and without MF $0.05-0.25(\mathrm{~g} / \mathrm{L})$ and the corresponding polarization parameter are tabulated in Table-1. Careful scrutiny of Fig.-2 depicts that the added MF extract alters the cathodic curves anodic curves to lesser values of current density leading to diminishing corrosion by adsorption of MF on the electrode 
RASĀYAN J. Chem.

Vol. 12 | No. 1 |272 - 277| January - March | 2019

surface. ${ }^{11}$ Hence the ethanol extract of MF leaves could be categories as mixed type. The corrosion potential shifted positive direction compared to that of blank inferring that the MF chiefly controls the reaction at the anode site. ${ }^{12}$ This is due to the fact that organic compounds get adsorbed at the active sites of MS and form a shielding layer over the electrode. The deposit developed by a weak force of interaction between the metal and the components of MF and the $\mathrm{I}_{\text {corr }}$ values decreases due to the blockage of anodic reaction. $^{13,14}$

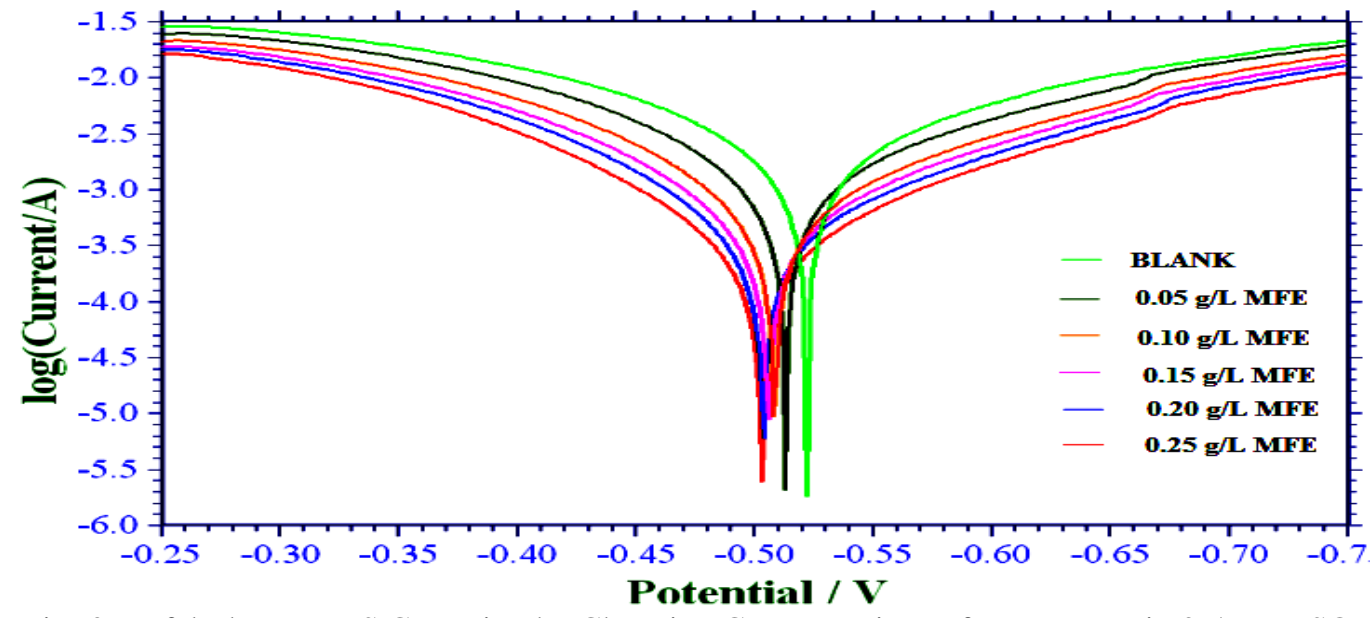

Fig.-2: Tafel Plots on MS Corrosion by Changing Concentrations of $M F$ Extract in $0.5 \mathrm{M} \mathrm{H}_{2} \mathrm{SO}_{4}$

\section{GCMS}

On comparing the GC retention indices of the constituents with respect to the retention time and on comparing with mass spectra libraries from Wiley and NIST, the constituents there in the MF extract were quantified. From the chromatogram (Fig.-3.) that it is well clear that out of 32 individual constituents four are prominent and they are listed in the Table-2.

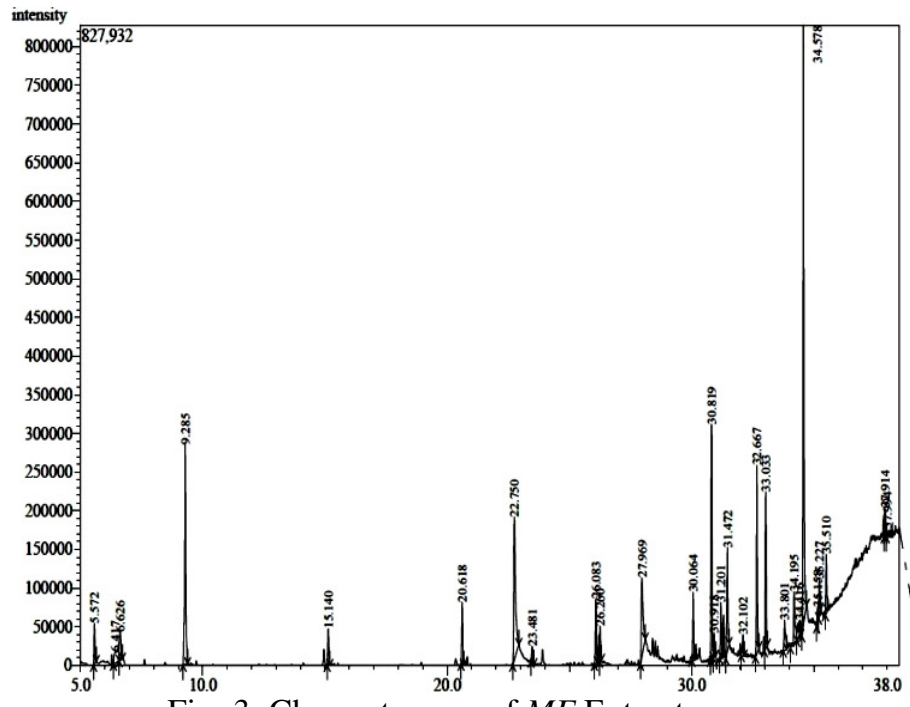

Table-2: GC MS Analysis of $M F$ Extract

\begin{tabular}{c|c}
\hline Compound name & $\begin{array}{c}\text { Molecular } \\
\text { Formula }\end{array}$ \\
\hline Styrene (CP 1) & $\mathrm{C}_{8} \mathrm{H}_{8}$ \\
\hline Dibutyl-phthalate (CP 2) & $\mathrm{C}_{16} \mathrm{H}_{22} \mathrm{O}_{4}$ \\
\hline $\begin{array}{c}\text { Isopropyl 2-phenyl-4,5- } \\
\text { dihydro-1,3-oxazole-4- } \\
\text { carboxylate (CP3) }\end{array}$ & $\mathrm{C}_{13} \mathrm{H}_{15} \mathrm{NO}_{3}$ \\
\hline $\begin{array}{c}\text { Benzamide,N-[1,2,3,4- } \\
\text { tetrahydro-2-(3-nitrophenyl)- } \\
\text { 4-oxo-3-quinazolinyl] (CP4) }\end{array}$ & $\mathrm{C}_{21} \mathrm{H}_{16} \mathrm{~N}_{4} \mathrm{O}_{4}$ \\
\hline
\end{tabular}

\section{SEM}

Fig.-3: Chromatogram of $M F$ Extract

Surface analysis of MS was calculated by scanning electron microscopy after $6 \mathrm{~h}$ immersion in the presence and absence of MF extract in $0.5 \mathrm{M} \mathrm{H}_{2} \mathrm{SO}_{4}$. Fig.-4A represents the photograph found for polished metal not including any aggressive solution while Fig.-4B showed strongly damaged MS surface due to the formation of corrosion products after in $0.5 \mathrm{M} \mathrm{H}_{2} \mathrm{SO}_{4}$ solutions. SEM micrographs of MS after in the presence of $0.25 \mathrm{~g} / \mathrm{L} \mathrm{MF}$ extract in $0.5 \mathrm{M} \mathrm{H}_{2} \mathrm{SO}_{4}$ is shown in Fig.-4C. Comparisons of figures show that there are no pits and fractures are observed in the micrographs in the inhibited MS. Thus it is clearly 
seen that the occurrence of good shielding layer over the MS surface which is responsible for corrosion inhibition.
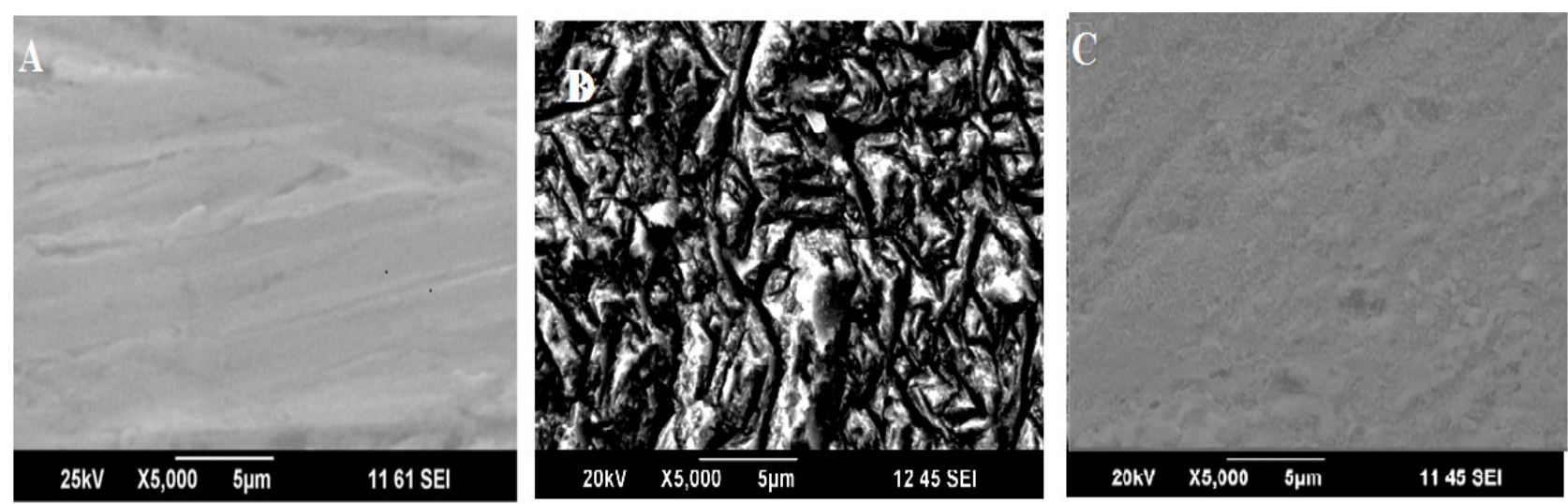

Fig.-4: SEM Micrograph of (A) Polished MS, (B)Uninhibited MS, (C) Inhibited MS in $0.5 \mathrm{M} \mathrm{H}_{2} \mathrm{SO}_{4}$

\section{ANOVA}

The values of IE calculated from PDP and EIS methods including and excluding MF extracts in $0.5 \mathrm{M}$ sulphuric acid as a function of the concentration of MF are given in Table-3. The table was rearranged into a matrix array. Matrix array is helpful for statistical analysis. The analysis of variance was employed on the data given in tables and the parameters like mean square (MS), degrees of freedom (Df), the sum of the squares,(SS), P, F and $\mathrm{F}_{\text {critical }}$ values were found out and listed in Table-3. From the tables it is clear that the calculated F-values are higher than the $F_{\text {critical }}$ values for the given degree of freedom and the $p$ values are less than 0.01 at $\mathrm{p}=0.01$. The results indicate the concentrations of MF extract have a significant role in the corrosion mitigation process and it is also clear that the interaction between the exposure time and the concentration of inhibitors are statistically significant and hence the null hypothesis s rejected. ${ }^{15,16}$

Table-3: Statistical Results for the IE and Concentration of $M F$ Extract in $0.5 \mathrm{M} \mathrm{H}_{2} \mathrm{SO}_{4}$ at $\mathrm{p}=0.01$

\begin{tabular}{c|c|c|c|c|c|c|c}
\hline \multirow{2}{*}{ System } & $\begin{array}{c}\text { Source of } \\
\text { Variance }\end{array}$ & SS & Df & MS & F-value & P-value & $F_{\text {critical }}$ \\
\hline \multirow{3}{*}{$\begin{array}{c}\text { MF in } \\
0.5 \mathrm{M}\end{array}$} & Concentration & 7312.662 & 5 & 1462.532 & 3.8960454 & 0.032059 & 3.3258345 \\
\cline { 2 - 8 } $\mathrm{H}_{2} \mathrm{SO}_{4}$ & IE & 15194.81 & 2 & 7597.406 & 20.238756 & 0.000305 & 4.102821 \\
\cline { 2 - 8 } & Error & 3753.89 & 10 & 375.389 & & & \\
\cline { 2 - 8 } & Total & 26261.36 & 17 & & & & \\
\hline
\end{tabular}

\section{Quantum Chemical Calculations}

To link the inhibition efficiencies and the constituents in MF extract, performed quantum chemical calculations using density functional theory (DFT) and the respective parameters were calculated. The structural aspect of the components of MF extract such as Styrene (CP 1), Dibutyl-phthalate (CP 2),Isopropyl 2-phenyl-4,5-dihydro-1,3-oxazole-4-carboxylate (CP3), Benzamide,N-[1,2,3,4-tetrahydro-2(3-nitrophenyl)-4-oxo-3-quinazolinyl] (CP4) and the performance of adsorption was used to identify the mechanism of inhibition. Table-4 listed the data obtained from DFT calculations values. The optimized structures, occupied and unoccupied molecular orbital structures of the investigated compounds are given in Fig.-5. The centers of adsorption of the CP1, CP2 and CP3 and the interaction with an electrode are predicted by FMO theory. ${ }^{17}$ The distance between the occupied and unoccupied molecular orbital of the compound is also an important factor that should be considered.

However, the greater the energy value of occupied molecular orbital greater the tendency to donate the electrons to an empty orbital of the $\mathrm{Fe}$ is greater tends to retard corrosion. However, the lower the unoccupied energy facilitates the gain of electrons from the metal surface and leading to lower the distance between LUMO-HOMO and improved the efficiency of inhibitor. A molecule having lower $\Delta \mathrm{E}$ is easily polarized and they are coupled with greater activity of the chemical constituents. Thus the molecules get adsorbed over the electrode surface at a greater extent. In the present case, the change 
RASĀYAN J. Chem.

Vol. 12 | No. 1 |272 - 277| January - March | 2019

energy values track the order of $\mathrm{CP} 3<\mathrm{CP} 1<\mathrm{CP} 4<\mathrm{CP} 1$, suggesting that $\mathrm{CP} 3$ has the greater affinity towards electrode in the acidic medium on comparing with other constituents and tend to interact stoutly with the electrode surface and prevent further deterioration of metal surface. From this parameter, it is evident that the CP3 shows better efficiency than others.

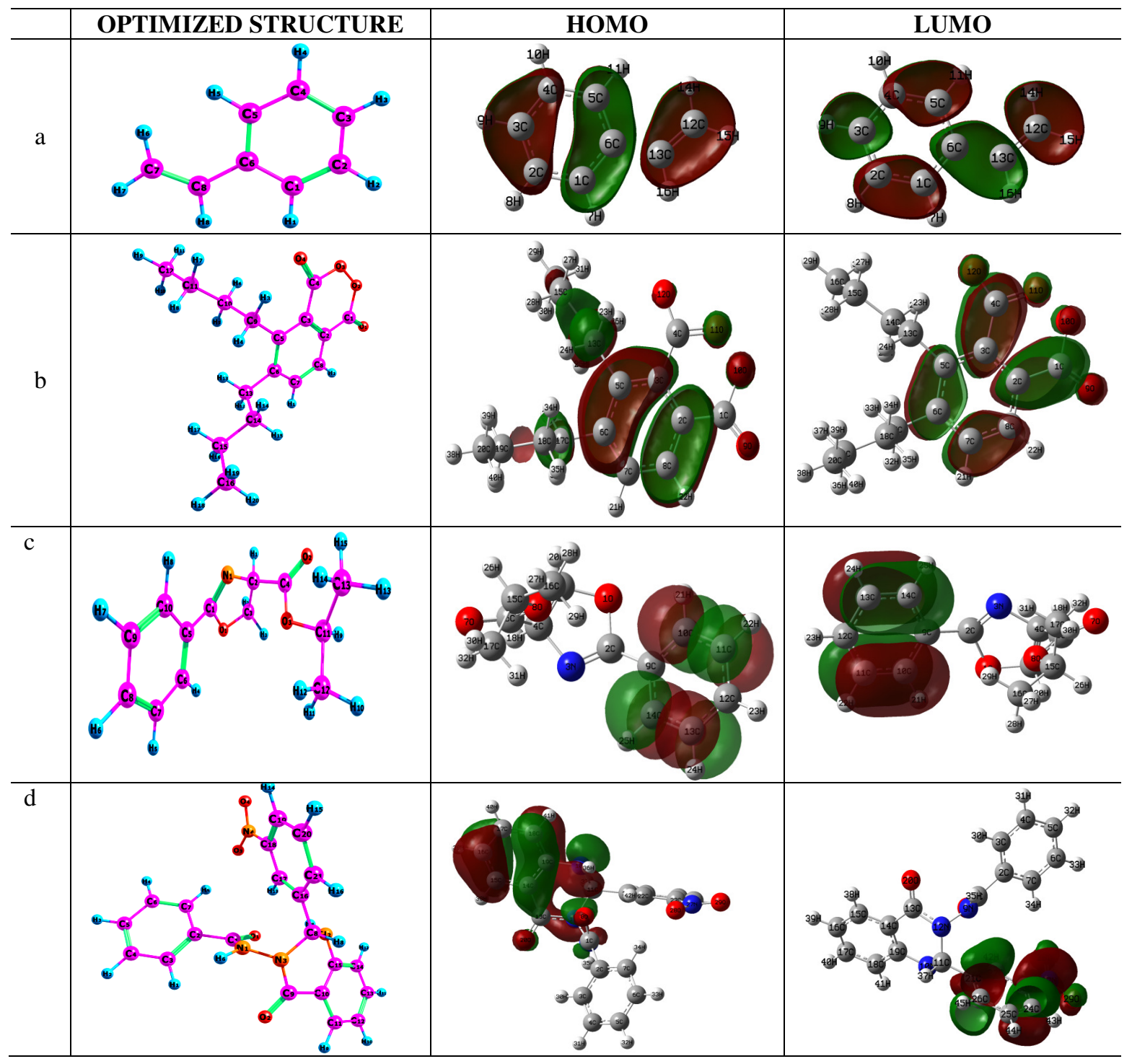

Fig.-5: Optimized, Highest Occupied Molecular Orbital and Lowest Unoccupied Molecular Orbital of (a) CP1, (b) $\mathrm{CP} 2$, (c) $\mathrm{CP} 3$ and (d) $\mathrm{CP} 4$

Table-4: Calculated Quantum- Chemical Parameters

\begin{tabular}{c|c|c|c}
\hline Compound & $\mathrm{E}_{\text {номо }}$ & $\mathrm{E}_{\text {LUMо }}$ & $\Delta \mathrm{E}$ \\
\hline CP1 & -6.1402 & -0.7938 & 5.3465 \\
\hline CP2 & -10.240 & -1.5910 & 8.6485 \\
\hline CP3 & -6.1720 & -3.7273 & 2.4447 \\
\hline CP4 & -9.4645 & -1.5176 & 7.9469 \\
\hline
\end{tabular}

CONCLUSION

The MF extract brings down corrosion considerably in both the acids. Effective concentration was found to be $0.25(\mathrm{~g} / \mathrm{L})$ for $\mathrm{MF}$ at room temperature in $0.5 \mathrm{M} \mathrm{H}_{2} \mathrm{SO}_{4}$. The negligible shift in $\mathrm{E}_{\text {corr }}$ values infers that 
RASĀYAN J. Chem.

Vol. 12 | No. 1 |272 - 277| January - March | 2019

extract of MF extract act as mixed nature. Enhancement of the charge transfer resistance values and fall of corrosion current and double layer capacitance values proved that the MF extract is cover mild steel surface with a layer of protective coating and inhibits further corrosion. GC-MS studies revealed that MF extract contains 32 components out of these 4 are prominent. The considerable development in surface topology in the presence of inhibited MS was confirmed by micrograph obtained from SEM. ANOVA studies explained the concentrations of MF extract have a significant role in the corrosion mitigation process and it is also clear that the interaction between the exposure time and the concentration of inhibitors are statistically significant. The obtained quantum chemical parameters indicate the Isopropyl 2-phenyl-4,5-dihydro-1,3-oxazole-4-carboxylate (CP3) effectively control the acid corrosion by the formation of an even film over the MS electrode surface.

\section{ACKNOWLEDGMENT}

The authors wish to acknowledge Sri Ramakrishna Mission Vidyalaya College of Arts and Science, Kumaraguru college of technology, Coimbatore, India, for providing the necessary facilities to carry out the studies.

\section{REFERENCES}

1. M.S. Abdelaal and A. E. El Saied, Transactions of SAEST, 16, 197(1981).

2. F. Bentiss, M. Traisnel, H .Vezin and M. Lagrenee, Journal of Industrial and Engineering Chemistry, 39, 3732(2000), DOI: 10.1021/ie000043o

3. S.K. Sharma , A. Mudhoo , G. Jain and E. Khamis, Green Chemistry Letters and Reviews, 2(1), 47(2009), DOI: 10.1080/17518250903002335

4. P. B. Raja and M. G. Sethuraman, Materials Letters, 62, 113(2008), DOI: 10.1016/j.matlet.2007.04.079

5. A.M. Fekry and M.A. Ameer, International Journal of Hydrogen Energy, 35, 7641(2010), DOI: 10.1016/j.ijhydene.2010.04.111

6. S. Jyothi and K. Rathidevi, Rasayan Journal of Chemistry, 10, 1253(2017), DOI: 10.7324/RJC.2017.1041924

7. ASTM G1-03, Standard Practice for Preparing, Cleaning, and Evaluating Corrosion Test Specimens, ASTM International, West Conshohocken, PA (2003).

8. S. Deng and X. Li, Corrosion Science, 52, 3840 (2010), DOI: 10.1016/j.corsci.2010.07.020

9. A.M. Fekry and R.R. Mohamed, Electrochimica Acta, 55, 1933(2010), DOI: 10.1016/j.electacta.2010.05.046

10. M. Behpour, S. M. Ghoreishi, M. Khayatkashani and N. Soltani, Corrosion Science, 53, 2489(2011), DOI: $10.1016 /$ j.corsci.2011.04.005

11. S. Jyothi and J. Ravichandran, Acta Metallergica Sinica, 27(6), 969(2014), DOI: 10.1007/s40195014-0107-6

12. N. Mu, X.H. Li, Q. Qu and J. Zhou, Corrosion Science, 48, 445(2006), DOI: 10.1016/j.corsci.2005.01.013

13. H. Keles, Materials Chemistry and Physics, 130, 1317(2011), DOI: 10.1016/j.matchemphys.2011.09.022

14. D. Jalajaa, J. Mallika and S. Jyothi, Rasayan Journal of Chemistry, 10,1271(2017), DOI: 10.7324/RJC.2017.1041926

15. P. R. Vittal and V. Malini, Statistical and Numerical Methods, Margham Publications, 1st edn. (2012).

16. A. S. Yaro, A. A. Khadom and R. K. Wael, Alexandria Engineering Journal, 52, 129(2013), DOI: 10.1016/j.aej.2012.11.001

17. J. Fang and J. Li, Journal of Molecular Structure, THEOCHEM 593, 179(2002), DOI: 10.1016/S0166-1280(02)00316-0

[RJC-4097/2018] 